\title{
EL DÓMINE CABRA DEL BUSCÓN: LECTURA DE LAS CLAVES SIMBÓLICAS
}

\author{
A Elizabeth Wilhelmsen \\ y Michael Ewbank, maximis cum gratiis
}

En Virtud militante. Contra las quatro pestes del mundo, inuidia, ingratitud, soberbia, avarizia, Quevedo, valiéndose de las autoridades bíblicas, patrísticas y escolásticas, ataca estos vicios con el rigor ético que distingue la cara austera de su personalidad. El escritor asigna a la avaricia la posición postrera porque constituye, conforme al pensamiento cristiano, una especie de summa vitiorum: "Siendo contra Dios, es soberbia, siendo contra sí ingratitud, siendo contra el próximo invidia. Beisla peste... Que no solamente es la quarta sino todas quatro"1. La célebre figu-

${ }^{1}$ Ed. A. Rey, Universidad, Santiago de Compostela, 1985, p. 168. Todas las citas de esta obra se refieren a esta edición. En el capítulo dedicado a la última "peste", Quevedo, después del exordio, describe la avaricia, utilizando como fuente la Summa Theologice de SAnto Tomás DE AQuino. Según declara el mismo don Francisco: "Sigamos en su definiçión la escuela scholástica, i oigamos la del doctor ánxel Sancto Thomás" (p. 167). El escritor no se atiene al orden riguroso de las argumentaciones tomistas sino que ensarta una serie de aserciones, sacadas del texto original (exactamente la 2a2æ, questio 118 de la Summa), que considera relevantes para el fin ético y didáctico que se propone. La primera afirmación - "Auarizia es desordenado amor de tener" (pp. 167-168) - es la traducción literal de una frase de Hugo de San Víctor (De Sacramentis, libro 2, parte 13, cap. 1) que Santo Tomás recoge en el articulus 1 de la questio 118 de su obra. A continuación escribe Quevedo: "La auaricia propiamente siempre es peccado. Es peccado spiritual". Estas palabras proceden del articulus 6 de la questio antedicha, en cuya responsio el Aquinatense sostiene que "avaritia est peccatum spirituale" ya que el avaro "delectatur enim... in hoc quod considerat se possessorem divitiarum". Quevedo sigue precisando la naturaleza de ese vicio: "La auarizia según que se opone a la justizia deste modo, de su jénero es peccado mortal”, casi una versión interlineal de la responsio del articulus 4 del compendio teológico tomis- 
ra del dómine Cabra del Buscón representa la personificación literaria del avaro, el cual, por pertenecer al clero secular, aparece, a través de las lentes implacables de don Francisco, más aborrecible aún. Leo Spitzer, en su ensayo de 1927 titulado "Zur Kunst Quevedos in seinem Buscón", había notado que el nombre Cabra "hat etwas Willentlich-Hindeutendes"2, pero tal observación había quedado sin desarrollarse. El presente trabajo parte de esta anotación spitzeriana y trata de investigar las razones de la elección del apellido caprino mediante el análisis de los valores simbólicos, subyacentes en el texto, de los componentes intratextuales y su relación con otras obras quevedianas. Creemos que el autor se sirve del signo cabra como el foco donde converge un haz de elementos heterogéneos, procedentes de los campos religioso, mitológico, literario y científico, y de las tradiciones populares. Este conjunto de enlaces es lo que vamos a examinar.

La cabra, en la mitología griega, estaba ligada sobre todo con el culto a Dionisos, el Baco de los romanos, divinidad de la vid,

ta: "Dicendum quod, sicut dictum est avaritia dupliciter dicitur. Uno modo secundum quod opponitur justitice, et hoc modo ex genere suo est peccatum mortale". Don Francisco añade que la avaricia "es medio entre los peccados puramente spirituales, i los puramente carnales", pasaje que representa una condensación de la responsio 1 del articulus 6 de la questio 118: "Rationem tamen objecti medium est inter peccata pure spiritualia, quæ quærunt delectationem spiritualem circa objecta spiritualia... et vitia pure carnalia, quæ quærunt delectationem pure corporalem circa objectum corporale". La formulación quevediana de la exposición tomista de la avaricia termina de la manera siguiente: "Es contra Dios, contra sí, i contra el próximo" (p. 168), nuevo caso de condensación y adaptación del original, precisamente la responsio 2 del articulus 1: "Et secundum hoc est directe peccatum in proximum, quia in exterioribus divitiis non potest unus homo superabundare nisi alter deficiat... Et sic avaritia est peccatum hominis in seipsum, quia per hoc deordinatur ejus affectus, licet non deordinetur corpus sicut per vitia carnalia. Ex consequenti autem est peccatum in Deum, sicut et omnia peccata mortalia, inquantum homo propter bonum temporale contemnit æternum”. Las cursivas evidencian las correspondencias exactas entre la Summa Theologie y Virtud militante. Las citas de la Summa que figuran en esta nota proceden del texto publicado por Blackfriars en Oxford en 1972.

2 Romanische Stil- und Literaturstudien, N. G. Elwert'sche Verlagsbuchhandlung (G. Braun), Marburg A. Lahn, 1931, t. 2, p. 75. El ensayo fue publicado por primera vez en ARom, 11 (1927), 511-580. La versión al castellano, "Sobre el arte de Quevedo en el Buscón", está incluida en Francisco de Quevedo, ed. G. Sobejano, Taurus, Madrid, 1978, pp. 123-184. Sobejano, autor de dicha versión, traduce la frase con "algo de adrede indicativo" (p. 144). 
a quien se inmolaba el animal durante las fiestas de pleno verano. Según la leyenda, el mismo Zeus, de niño, se alimentó de la leche de la cabra Amaltea, que tenía un cuerno rebosante del líquido nutritivo y todo tipo de frutas, cuerno que se convirtió en el símbolo de la abundancia, la cornucopia ${ }^{3}$. Esta puede leerse como subtexto irónico del episodio del licenciado Cabra: la única cosa que abunda en su pupilaje es, paradójicamente, la penuria, así que el dómine podría encarnar la cornu-inopia. La descripción del personaje se caracteriza, a nivel lingüístico, precisamente por la presencia de la partícula negativa "no" y de la preposición "sin", que expresa falta o carencia, y estos privativos reflejan la miseria moral y material del pupilero: las "búas"4 que desfiguran su hiperbólica nariz "no fueron de vicio", es decir, no son la consecuencia de una enfermedad venérea, porque el sexo cuesta dinero, sino de un simple "resfriado" no curado, porque las medicinas también cuestan dinero. Entonces el no-vicio de la lujuria deriva de otro vicio que Cabra no confiesa, el de la avaricia; al clérigo, observa el narrador, le faltan "no sé cuántos" dientes (p. 33), su sotana "no se sabía de qué color era" y aparece "sin pelo", "sin ceñidor" y no tiene ni "cuello ni puños" (p. 34); Cabra nunca se corta la barba "por no gastar" (p. 33) y en la cama duerme siempre de un lado "por no gastar las sábanas" (p. 34) y es, incluso, avaro de palabras: "nos hizo una plática corta, que aun por no gastar tiempo no duró más" (p. 35). A causa de la escasez de comida los estudiantes están reducidos a esqueletos andantes y uno de ellos muere literalmente de inanición. El clérigo, obsesionado por el " no gastar", gasta su misma salud y de ahí que los órganos de su cuerpo causan la impresión de que quieren comerse a sí mismos, en un desesperado impulso de autofagia: "las barbas descoloridas de miedo de la boca vecina, que, de pura hambre, parecía que amenazaba a comérselas"; "el gaznate... con una nuez tan salida, que parecía se iba a buscar de comer forzada de la necesidad" (p. 33).

En la Sagrada Escritura la cabra se encuentra muchísimas veces y tal profusión se debe a la importancia que ese mamífero tenía en la economía de las poblaciones del Cercano Oriente an-

${ }^{3}$ La narración aparece en los Fasti de Ovidio, libro 5, vv. 115-128.

${ }^{4}$ Francisco de Quevedo, La vida del Buscón llamado don Pablos, ed. F. Lázaro Carreter, Universidad, Salamanca, 1980. En adelante indico la página; las cursivas siempre son mías. 
tiguo. Según las normas del Antiguo Testamento se consideraba como animal de sacrificio: durante el día de la Expiación se escogían dos cabras, una para la purificación de los pecados y la otra, un macho cabrío, representaba el chivo expiatorio que llevaba simbólicamente sobre sí todas las culpas del pueblo de Israel y se abandonaba en el desierto (Levítico, 16, 6-26). Si tenemos en cuenta ese subtexto bíblico, Quevedo realiza una nueva inversión de valores: el licenciado no es un capro espiatorio, no es sacrificado ni se sacrifica por amor de Dios; al contrario, los estudiantes son las víctimas designadas que expían el pecado de la avaricia de su preceptor. Cabra come apenas lo suficiente para alimentar el cuerpo; es avaro consigo mismo y, a la vez, condena hipócritamente el vicio de la gula: "Cierto que no hay tal cosa como la olla... todo lo demás es vicio y gula" (p. 36) $)^{5}$. La "dieta" (p. 40) que el clérigo alaba procede del appetitus inordinatus del avaro, en conformidad con la definición de Santo Tomás ${ }^{6}$, y no del ejercicio virtuoso de la abstinencia y penitencia.

El nombre Cabra es la expresión de la fisiognómica y etopeya del personaje quevediano. James Iffland recalca que "humananimal comparison is one of the many ways in which Quevedo degrades his characters" y prosigue: "Such comparisons at Quevedo's time received an extra impulse through the circulation of the doctrine... which said that one could tell much about the character of a man by determining the proximity of his physiognomy to that of some member of the animal kingdom"7. La cabra tiene pies delgados y largos y una barba que le cuelga de la mandíbula inferior. Cuando examinamos el aspecto físico del pupilero, su caprinidad se hace patente: "Él era un clérigo cerbatana, largo sólo en el talle... las barbas descoloridas... los brazos secos, las manos como un manojo de sarmientos cada una... con dos piernas largas y flacas" (pp. 32-33). El lexema cerbatana indica, traslaticiamente, según el Dicc. Aut., "todo lo que es hueco, estrecho, y largo" 8 y por lo tanto conlleva, simbólicamente, la oquedad, la vacuidad moral del dómine. Las manos, órganos

${ }^{5}$ Quevedo expresa la misma idea en el "tratado" sobre la avaricia: "A su cuerpo que se sustenta con las viandas se las niega por ahorrar, i a su alma que no come, la ruega con los mantenimientos... El auaro aun a sí mismo se destruie" (Virtud militante, pp. 187-188).

${ }^{6}$ Summa Theologice, Blackfriars, Oxford, 1963, p. 60. La cita proviene de la 1a2æ, questio 84, articulus 1, responsio.

${ }^{7}$ Quevedo and the grotesque, Tamesis, London, 1978, p. 110.

8 Ed. facs., Gredos, Madrid, 1976, s.v. 
prensiles e imagen emblemática del avaro que se agarra a sus posesiones, han adquirido la apariencia de tallos vegetales, nueva inversión de valores. La referencia a los "sarmientos" cae dentro del campo semántico de la vid, asociada, como hemos visto, con los ritos dionisíacos y la inmolación de la cabra. Un refrán popular también presenta la correlación cabra-vid, debido a la voracidad insaciable del rumiante: "Cabras en viña, peor que la peor pedrisca" . En la visión cristiana, la vid es la efigie de Cristo y los vástagos la de los apóstoles: "Ego sum vitis, vos palmites" 10 , afirma Jesús en el Evangelio de San Juan $(15,5)$. Quevedo invierte otra vez los valores, deshumanizando al pupilero con una metáfora vegetal y aplicándola a la parte de su cuerpo que es el instrumento del pecado; dice San Gregorio Magno, "Arma quippe peccantium sunt membra corporis, quibus perversa desideria quæ concipiunt exsequuntur"11. En este caso, la vid puede ser la avaricia, los vástagos físicos, las manos, y los metafóricos, todos los vicios que aquélla engendra. El juego de palabras conseguido mediante la homonimia entre la forma femenina del adjetivo "romo" y la ciudad italiana ("la nariz, entre Roma y Francia”) se relaciona también con el aspecto cabruno, según la explicación de Covarrubias: "A la cabra le dieron el epícteto de sima o roma, por tener las narizes chatas... Este epícteto de sima le da Virgilio en el lugar alegado, Égloga 10"12. Los huesos del licenciado, cuando se descomponen, suenan "como tablillas de San Lázaro", símil auditivo de carácter irónico puesto que estas últimas producen un sonido conectado con el pedir limosna, mientras que aquellos crujen por razones nada caritativas. La avaricia es inconciliable con la caridad, virtud fundamental en la ética cristiana. Las piernas "largas y flacas" se parecen a un "tenedor o compás" (p. 33); el primer objeto contiene otro matiz irónico tratándose de un utensilio que

${ }^{9}$ Refranero general ideológico español, comp. L. Martínez Kleiser, Madrid, 1953, p. 93.

10 Biblia Sacra Juxta Vulgatam Clementinam, Desclée, Paris, 1938. Todos los pasajes bíblicos proceden de esta edición y las cursivas son mías.

11 Moralium Libri sive Expositio in Librum B. Job, al cuidado de J. P. Migne, Paris, 1844-1864, t. 75, p. 913.

12 Tesoro de la lengua castellana o española, ed. facs., Turner, Madrid, 1979, p. 255. El pasaje virgiliano al que se refiere Covarrubias es el siguiente: "sollicitos Galli dicamus amores, / dum tenera attondent simæ uirgulta capellæ" (Égloga X, vv. 6-7), cf. Publio Virgilio Marón, Opera, ed. R. A. B. Mynors, Clarendon, Oxford, 1969, p. 25. 
sirve para comer aplicado a un hombre que encarna "la hambre viva" (p. 32); en cuanto al segundo instrumento, en la Iconologia (1611) de Cesare Ripa simboliza "l'ordine, \& misura in tutte le cose" y, junto con una bolsa, forma parte del emblema de la parsimonia, la cual "non eccede[ndo] il modo dell'honesto, \& del ragioneuole"13, se contrapone por su moderación a la avaricia.

El narrador anota que los ojos de Cabra están "avecindados en el cogote" y parece que miran "por cuévanos, tan hundidos y oscuros, que era buen sitio el suyo para tiendas de mercaderes" (pp. 32-33). El pupilero mira como a través de un túnel profundo y lóbrego, y por consiguiente el campo visual que puede abarcar es estrecho, y el enfoque de la realidad circundante muy limitado. Ya que en Virtud militante Quevedo sostiene que el avaro "haze volsa su alma" (p. 188), aquí podríamos extender la metáfora y decir que, de forma paralela, el avaro hace bolsa sus ojos porque no ve más que los bienes materiales. Cabra, observa acertadamente B. W. Ife, "has a mercantile outlook on life, seeing everything in terms of its commercial value..."14. San Isidoro de Sevilla refiere que los griegos llamaban a algunas cabras salvajes dorkás por la gran agudeza de su percepción, que les permite ver, desde las más elevadas montañas, a todo el que se aproxima ${ }^{15}$. Los bestiarios medievales incorporan tal cualidad al simbolismo cristiano: en De Bestiis et Aliis Rebus, obra atribuida a Hugo de San Víctor, esa facultad visiva del animal se configura como el símbolo de la omnisciencia de Dios y Cristo, el cual previó la traición de Judas: "Nam sicut caprea venatorem prævidet, ita Dominus noster Jesus Christus longe prospiciens Judam proditorem, sic aiebat: Unus ex vobis me traditurus est (Matth. xxvi)"16. La vista del licenciado carece de luz moral y espiritual; sus ojos son oscuros "cuévanos" (p. 32), palabra en que resuena el lexema cueva, y que, por ser cestos hondos usados generalmente para la vendimia, se vinculan semánticamente con la vid, lo cual, junto con "sarmientos" (p. 33), refuerza el simbolismo caprino. La clarividencia de la cabra se ha transformado en la visión miope del Cabra.

13 Ed. facs., Garland, New York, 1976, p. 410.

14 Anotación a La vida del Buscón llamado don Pablos, Pergamon Press, Oxford, 1977, p. 202.

15 Etimologías, eds. J. Oroz Reta y M.-A. Marcos Casquero, BAC, Madrid, 1982 , t. 1, pp. 58-59.

16 PL, t. 177 , pp. $63-64$. 
La fisiognómica del pupilero muestra otros dos animales emblemáticos: el avestruz y la rana. El primero es el término de comparación del garguero del personaje quevediano: "el gaznate largo como de avestruz" (loc. cit.). Este último es animal voraz, capaz de tragar cualquier cosa, comestible y no comestible, y tal voracidad contrasta irónicamente con la "dieta" autoimpuesta de Cabra y que él impone a los estudiantes de su pupilaje. En el libro de Job (39, 13-18), el avestruz es el vivo ejemplo de la crueldad maternal, porque abandona los huevos que ha puesto después de haberlos cubierto de arena. Los Moralium Libri de San Gregorio Magno glosan minuciosamente el texto bíblico antedicho y descubren un valor simbólico del avestruz que se adapta a la etopeya de Cabra: la hipocresía. Esa actitud de falsedad, de ocultamiento de las verdaderas intenciones, es sinónimo de la fallacia de la cual habla Hugo de San Víctor y que forma parte del comitatus de la avaricia ${ }^{17}$. El comentario gregoriano hace hincapié en que el avestruz, aunque tiene plumas semejantes a las de la garza y del gavilán, no puede alzarse del suelo a causa del peso de su cuerpo. Al igual que el ave corredora, los hipócritas "alas per figuram sanctitatis extendunt, sed curarum sæcularium pondere prægravati, nullatenus a terra sublevantur". Cabra simula la "bonorum vitam" pero no posee la "veritatem sanctæ actionis"18. Cuando don Diego y Pablos tratan de comunicar su condición de hambrientos, el clérigo, hipócritamente, oculta la verdad: "Quejábamonos nosotros a don Alonso, y el Cabra le hacía creer que lo hacíamos por no asistir al estudio" (p. 45). El clérigo muestra también su hipocresía al reprender el vicio de la gula, siendo él mismo esclavo de un vicio mucho más reprensible, y en las irónicas, casi sarcásticas, exhortaciones que dirige a sus famélicos estudiantes: "Coman, que me huelgo de verlos comer", "Coman, que mozos son y me huelgo de ver sus buenas ganas" (p. 37), "Coman como hermanos, pues Dios les da con qué" (p. 38). Santo Tomás de Aquino, al interpretar un pasaje del Evangelio de

${ }^{17}$ De Fructibus Carnis et Spiritus, PL, t. 176, p. 1001. Esta obra contiene también los dibujos del "arbor vitiorum" y del "arbor virtutum". Una de las ramas del primer árbol, cuya raíz es la "superbia", termina precisamente en la "avaritia", rodeada de siete hojas más pequeñas e iguales que simbolizan los siete vicios que aquélla engendra, es decir: 1) philargyria (en griego "amor al dinero"), 2) perjurium, 3) violentia, 4) usura, 5) fraus, 6) rapina y 7) fallacia. Véanse las pp. 1007-1008.

18 PL, t. 76, p. 578. 
San Mateo, en el que Cristo lanza una invectiva contra los fariseos, comenta que la hipocresía comprende también el pecado de la avaricia ${ }^{19}$. Además, se pueden establecer interesantes puntos de contacto entre la De Humana Physiognomonia (1586) de Della Porta y la descripción del licenciado Cabra del Buscón. Asevera el erudito italiano en el libro segundo de su obra: "Exiguum caput, cum inconcinna figura, et ei par debilitas colli, et dorsi, defectum significat virtutis moralis... et ob id homo ille perfidus, velocis iræ"; y continúa: "Ego ad struthiocamelum referrem: nam inter animalia exiguum retinet caput, ceruix procera est, corporis eximia magnitudo"20. Algunos rasgos fisiognómicos y temperamentales del personaje quevediano son muy parecidos a los que señala Della Porta: Cabra tiene "una cabeza pequeña" (p. 32, el "exiguum caput" dellaportiano); su aspecto físico y manera de hablar — "la habla ética" (p. 33)indican falta de elegancia y armonía ("inconcinna figura"); él carece de virtud ("defectum... virtutis moralis"); es desleal y falso ("perfidus") y es propenso a enfadarse ("velocis iræ"), como se deduce de los ejemplos siguientes: "Enojóse mucho, y díjome que aprendiese modestia" (p. 37), "Enojóse Cabra conmigo, y dijo que él me echaría de su casa" (p. 44), "Cabra se enojó de que se lo preguntase" (p. 42). Della Porta ilustra sus teorías con el busto de un hombre de cabeza pequeña junto con la imagen entera de un avestruz y los dos elementos figuran en el retrato del dómine. No se trata de meras coincidencias ya que el Índi$c e$ del Monasterio de San Martín de Madrid (1788) registra unas obras del italiano que Quevedo poseía en su biblioteca privada, incluyendo un ejemplar de Della fisionomia dell'huomo ${ }^{21}$. Conviene recordar que Quevedo, en La providencia de Dios (1642), se refiere a su encuentro en Nápoles con Giambattista Della Porta, a quien juzga "hombre curiosamente docto"22.

19 "Post hoc exponit sic et vos foris quidem apparetis hominibus iusti, idest homines vos iudicant iustos, intus autem pleni estis hypocrisi et iniquitate. Comprehendit peccata carnalia, avaritiam et gulam... sub qua vanagloria continetur" (Super Evangelium S. Matthei Lectura, cura R. Cai, Marietti, Torino, 1951, p. 291).

20 Ed. facs., Aux Amateurs de Livres, Paris, 1990, p. 32.

21 Alessandro Martinengo, La astrología en la obra de Quevedo: una clave de lectura, Alhambra, Madrid, 1983, p. 179.

22 Francisco de Quevedo y Villegas, Obras completas, ed. F. Buendía, Aguilar, Madrid, 1967-1974, t. 1, p. 1568. Eugenio AsEnsio llama la atención sobre este encuentro en su obra Itinerario del entremés: desde Lope de Rueda a Quiñones de Benavente, Gredos, Madrid, 1965, donde observa también que: "Sin 
El otro animal, la rana, es un vehículo de representación simbólica de la sotana "milagrosa" (nótese la ironía del adjetivo) del pupilero, la cual, a consecuencia del "no gastar", se ha convertido casi en el tegumento que cubre su piel humana: "Unos, viéndola tan sin pelo, la tenían por de cuero de rana" (p. 34). Según el relato del Éxodo (8, 1-15), la segunda plaga de Egipto fue efecto de una invasión de ranas, que los judíos consideraban como criaturas inmundas ${ }^{23}$, y Whittlesey agrega que "in Christian art, the frog is a symbol of repulsive sin..."24. La suciedad física del clérigo es una de sus características, desde el bonete "ratonado con mil gateras y guarniciones de grasa... con los fondos en caspa", hasta "la sotana mísera y corta" (p. 34) y la carne que se le pega a las uñas. El asco que todo ello comunica al lector va acompañado de la repulsión por la avaricia, evocada a través de la sensación táctil de la piel húmeda de la rana, y su naturaleza de plaga o, mejor dicho, de "peste" del mundo, según la definición de Virtud militante. Es digno de interés que la descripción de uno de los emblemas de la codicia, contenido en la Iconologia de Ripa, presenta otro anfibio, el sapo, como símbolo de tal vicio: "Le si dipinge il rospo, nella destra mano, il quale, tutto che habbia grandissima copia della terra, della quale si pasce, nondimeno sempre teme, \& si astiene di quella, desiderandone sempre più"25. El Apocalipsis de

abandonar el viejo repertorio, el entremés, igual que la sátira, empleaba diferentes estratagemas para captar las mil facetas del hombre encubierto tras sus mimetismos. Quevedo usó, para reflejar esta duplicidad del hombre, diversos procedimientos literarios... La animalidad escondida tras lo humano ha servido de nota sugestiva a Quevedo en numerosos pasajes, especialmente en El Buscón y el entremés de La venta" (p. 180).

${ }^{23}$ Louis Charbonneau-Lassay, Le bestiaire du Christ, Desclée, DeBrouwer, Bruges, 1940, p. 826.

${ }^{24}$ Symbols and legends in Western art. A museum guide, Scribner's, New York, 1972, p. 119. DAVID P. Russi opina lo mismo: "This description carries implicitly the idea of the cassock which, being 'sin pelo', was so worn by use that it seemed as smooth as a frog's skin. But quite besides the literal, the frog adds a connotation of repulsiveness to this man, described in such an extremely grotesque manner" ("The animal-like world of the Buscón", $P h Q, 66$, 1987, p. 441).

${ }_{25}$ Op. cit., p. 34. Adolf Katzenellenbogen nos informa en una nota que "snakes and toads... also served in a general way to torment sinners, the avaricious man for instance, as shown in an illustration of hell in the Beatus Apocalypse from Santo Domingo de Silos, completed 1109" (Allegories of the virtues and vices in Mediaeval art from Early Christian times to the thirteenth century, Norton, New York, 1964, p. 58). 
San Juan vincula el carácter inmundo de las ranas a un elemento que, desde nuestro punto de vista, es fundamental: lo satánico. El pasaje juanino reza así: "Et vidi de ore draconis, et de ore bestiæ, et de ore pseudoprophetæ, spiritus tres immundos in modum ranarum. Sunt enim spiritus damoniorum facientes signa" (16, 13-14).

Reanudando un hilo precedente, es oportuno añadir que otro texto bíblico, el de Isaías, pone al avestruz en relación con el demonio: "Sed requiescent ibi bestiæ, et replebuntur domus eorum draconibus, et habitabunt ibi struthiones, et pilosi saltabunt ibi" $(13,21)$; "et erit cubile draconum, et pascua struthionum" $(34,13)$. Con el vocablo "pilosi”, explica San Jerónimo en su comentario al libro profético, se indican los "incubones" o "satyros", pertenecientes al género de los demonios 26 y que, según la interpretación de John M'Clintock y James Strong, designan las cabras, especialmente los machos cabríos ${ }^{27}$. San Gregorio Magno nos ofrece más detalles: los miembros de los "pilosi" empiezan en forma humana pero "bestiali extremitate termina[n] tur" y, metafóricamente, representan la "peccati asperitas" 28 , lo cual nos hace pensar en el pelo áspero de la cabra.

La onomástica del dómine Cabra no sólo refleja su fisiognómica, sino que revela también su índole demoníaca. En la antigüedad clásica se encuentran demonios cabrunos y divinidades mitad hombres y mitad animales, como el dios griego Pan, el Fauno romano, a quien se imaginaba provisto de piernas, cola, cuernos y barba de cabra, y de las demás partes del cuerpo de naturaleza humana. El simbolismo caprino, desde la vertiente cristiana, se expresa con la mayor claridad en el Evangelio de San Mateo donde Dios separa las ovejas ("oves") de las cabras ("hædos"), respectivamente los justos de los condenados a la perdición eterna: "Et congregabuntur ante eum omnes gentes, et separabit eos ab invicem, sicut pastor segregat oves ab hædis; et statuet oves quidem a dextris suis, hædos autem a sinistris" (25, 32-33). Charbonneau-Lassay destaca que el macho

${ }^{26}$ Commentariorum in Isaiam Prophetam, PL, t. 24, p. 159.

27 "SATYR, the rendering in Isa. xiii, 21; xxxiv, 14, of the Heb. word... säir', which properly means hairy; hence a goat, especially a he-goat... According to the old versions, and nearly all the commentators, our own translation is correct, and satyrs - that is, daemons of woods and desert places, half men and half goats- are intended" (Cyclopedia of biblical, theological and ecclesiastical literature, Harper, New York, 1884-1896, s.v.).

28 Moralium libri, PL, t. 75, p. 786. 
cabrío es el emblema del monarca del infierno y los demonólogos medievales representaban a Satanás casi exclusivamente bajo ese aspecto animal (p. 185). La creencia de que el diablo tenía un pie en forma de pezuña de cabra y en los aquelarres aparecía como cabrón, estaba profundamente arraigada en la cultura popular de toda Europa durante la Edad Media. Covarrubias recoge esa tradición y así define al cabrón: "Es sýmbolo del demonio, y en su figura cuentan aparecerse a las bruxas y querer ser reverenciado dellas" (p. 256). Cervantes también dedica una parte relevante del Coloquio de los perros a las artes mágicas de la Cañizares, la cual, creyendo que Berganza es el hijo de la Montiela transformado en perro, le narra sus experiencias de hechicera y sus relaciones con las potencias infernales:

Muchas veces he querido preguntar a mi cabrón qué fin tendrá vuestro suceso, pero no me he atrevido, porque nunca a lo que le preguntamos responde a derechas, sino con razones torcidas y de muchos sentidos. Así, que a este nuestro amo y señor no hay que preguntarle nada, porque con una verdad mezcla mil mentiras... Vamos a verle... a un gran campo, donde nos juntamos infinidad de gente, brujos y brujas, y allí nos da de comer desabridamente, y pasan otras cosas que en verdad, y en Dios y en mi ánima, que no me atrevo a contarlas, según son sucias y asquerosas, y no quiero ofender tus castas orejas ${ }^{29}$.

Ya al principio del Buscón se alude al diablo cuando Pablos recuerda las actividades brujeriles de su madre: "Sólo diz que se dijo no sé qué de un cabrón y volar, lo cual la puso cerca de que la diesen plumas con que lo hiciese en público" (p. 17). El hecho de que el cabrón se mencione en los primeros párrafos de la obra es significativo ya que no sólo constituye una anticipación del clérigo cabruno, sino que ofrece también la clave interpretativa del personaje mismo. El capítulo siete del libro primero del Buscón reitera las prácticas de la madre del protagonista, a través de las palabras de Alonso Ramplón, el tío verdugo: "Dícese que daba paz cada noche a un cabrón en el ojo que no tiene niña" (pp. 92-93) ${ }^{30}$.

29 Novelas ejemplares, ed. J. Rodríguez-Luis, Taurus, Madrid, 1983, t. 2, p. 267.

${ }^{30}$ Este vulgar acto de demoniolatría lo ilustra un grabado de Francesco Maria Guazzo, autor del Compendium Maleficarum (1608 y 1626), reproducido en la fig. 7 de Las brujas y su mundo de Julio Caro Baroja, Revista de Occidente, Madrid, 1961, que contiene también la descripción de los ritos de 
Volviendo al dómine Cabra, si su nombre está estrechamente unido con la idea del demonio, no nos basamos solamente en este factor para afirmar que el personaje tiene características diabólicas. Otros componentes textuales corroboran la lectura que proponemos. Empecemos por la escena del refectorio, cuya angostura espacial - "un medio celemín” (p. 35) - se conforma bien con la estrechez moral del pupilero: "Sentóse el licenciado Cabra y echó la bendición. Comieron una comida eterna, sin principio ni fin" (p. 36). El clérigo bendice pero su acción no entraña ninguna significación sagrada; cae más bien sobre los estudiantes hambrientos como una maldición. En efecto, cuando Cabra vuelve a bendecir los mezquinos restos del pasto, destinados a los criados - "unos mendrugos... dos pellejos y unos güesos" (p. 37) - el narrador, con un perfecto contrapunto de voces, le echa a él precisamente una maldición: “¡Mal te haga Dios y lo que has comido, lacerado... que tal amenaza has hecho a mis tripas!" (loc. cit.).

La comida, que se califica de "eterna", dura el lapso de tiempo de un alimento desprovisto de cualquier sustancia, prácticamente inexistente y, por ende, "sin principio ni fin". Un crítico interpreta la frase final en el sentido de que "no tenía ni entrante, o ante - principio-, ni postre - fin-, a pesar de que los pupileros estaban obligados a incluirlos en el menú"31. En nuestra opinión, debajo del nivel denotativo que acabamos de citar, se hallan unas connotaciones teológicas que informan todo el discurso quevediano y le confieren cohesión semántica. Es menester subrayar que tales connotaciones están documentadas en otros textos del Siglo de Oro. El ejemplo más pertinente es uno de los cuentos recogidos por Juan de Arguijo, exactamente el núm. 318 de la edición de Beatriz Chenot y Maxime Chevalier: "Farfán: diéronle un día el caldo y la ración a comer, sin ante ni postre, y dijo: -Sin ser Dios, no ten [go] principio ni fin" ${ }^{2}$. El chiste del maestro agustino, corriente entre los frailes

adoración del demonio de una sociedad secreta alemana durante la Edad Media. Véanse las pp. 117-119.

${ }^{31}$ Anotación de Fernando Cabo Aseguinolaza a su edición de La vida del Buscón, Crítica, Barcelona, 1993, p. 69. El crítico cita la entrada ante del Tesoro de la lengua castellana o española, p. 124.

${ }^{32}$ Cuentos recogidos por Juan de Arguijo y otros, Diputación Provincial, Sevilla, 1979, p. 142. La conexión entre el cuento de Arguijo y el pasaje del Buscón ha sido señalada por Maxime Chevalier en su ensayo "Cuentecillos y chistes tradicionales en la obra de Quevedo”, NRFH, 25 (1976), 17-44. Véa- 
y los estudiantes, combina lo culinario y lo teológico mediante la utilización ingeniosa de la dialogía.

La noción de eternidad del Ser divino, a la que aluden los textos de Quevedo y el de Arguijo, se atestigua ya en la Sagrada Escritura y se desarrolla a través de algunos pensadores de la antigüedad (sobre todo San Agustín y Boecio) hasta encontrar su síntesis doctrinal más profunda en la Summa Theologice, tomista. Durante el siglo xvi, la idea se reelabora en las Disputationes Metaphysica de Francisco Suárez ${ }^{33}$. Básicamente, la eternidad de Dios hay que entenderla como una duración inmutable e interminable, caracterizada por la perfecta posesión de la plenitud del Ser, de la cual queda excluida la sucesión que, al contrario, marca la trayectoria de la existencia terrenal. Ahora bien, dado que al recibir las especies sacramentales los fieles asimilan, de acuerdo con la teología católica, la presencia real de Cristo, es lícito afirmar que la comunión constituye una "comida eterna". El Evangelio de San Juan nos proporciona las bases de esta interpretación cuando pone en boca del Salvador las siguientes palabras: "Ego sum panis vivus... Si quis manducaverit ex hoc pane, vivet in æternum... Qui manducat meam carnem, et bibit meum sanguinem, habet vitam æternam" $(6,51-52,55)^{34}$. Hay

se también del mismo autor, Quevedo y su tiempo: la agudeza verbal, Crítica, Barcelona, 1992, y en particular las pp. 120-121.

33 Sobre el concepto de eternidad consúltense las siguientes obras: BoEcio, De Consolatione Philosophice, libro 5, prosa 6, PL, t. 63, pp. 858-862; SAN Agustín, De Civitate Dei, libro 11, cap. 6 y libro 12, cap. 15, PL, t. 41, pp. 321322 y 363-365; SAnto Tomás de AQuino, Summa Theologice, 1a, questio 10, y Francisco SuÁrez, Disputaciones metafísicas, eds. S. Rabade Romeo, Salvador Caballero Sánchez y Antonio Puigcerver Zanón, Gredos, Madrid, 1966, t. 7. Léanse las secciones 3 y 4 de la disputatio L.

34 Un fragmento del Evangelio de San Juan se menciona en la Introduction à la vie dévote de San Francisco de Sales, que Quevedo tradujo del francés para restituir a ese "tesoro", "desfigurado" por una versión anterior al castellano, su "pureza" original, como declara el mismo escritor dirigiéndose "al pueblo católico cristiano" (Obras completas, t. 1, p. 1742). Reproducimos a continuación el texto salesiano y la traducción de don Francisco: a) "Le Sauveur a institué ce Sacrement très auguste de l'Eucharistie qui contient réellement sa chair et son sang, afin que qui le mange vive éternellement; c'est pourquoi, quiconque en use souvent avec dévotion affermit tellement la santé et la vie de son âme, qu'il est presque impossible qu'il soit empoisonné d'aucune sorte de mauvaise affection" (SAn Francisco de Sales, Euvres, al cuidado de André Ravier, con la colab. de Roger Devos, Gallimard, Bruges, 1969, p. 116, las cursivas se refieren al pasaje de San Juan); b) "El Salvador ha instituido el sacramento de la Eucaristía, que contiene realmente su car- 
que advertir que la expresión "sin principio ni fin" del Buscón contiene un eco de dos libros bíblicos, uno veterotestamentario (Isaías, 41, 4; 44, 6 y 48, 12) y el otro novotestamentario (Apocalipsis, 1, 8; 21, 6 y 22, 13). En el primero, a Dios se le atribuyen las cualidades de "primus et novissimus" y en el segundo, las de "Alpha et Omega, principium et finis". La última fórmula quiere indicar, mediante las letras inicial y final del alfabeto griego, que el Señor, siendo infinito, abarca la realidad entera: para citar la glosa de San Alberto Magno, Él es el principium "a quo sunt omnia creata" y el finis "ad quem omnia sunt ordinata" 35 . Estos subtextos nos permiten dilucidar el mecanismo de la ironía quevediana: el adjetivo "eterna", aplicado a la comida del pupilaje, contrasta marcadamente con el pasto consagrado de la comunión y el uso del privativo "sin" y de la conjunción negativa "ni", antepuestos por lo general a "principio" y "fin" para definir el concepto de eternidad, revelan aquí la ausencia completa de lo escatológico (en la acepción elevada del término). El simbolismo eucarístico, que el episodio del refectorio encierra de manera algo hermética, se evidencia en otra escena paralela, como veremos más adelante.

Después de tal episodio, ocurre un incidente en apariencia trivial pero que a la luz de lo dicho adquiere cierto relieve. Nos referimos al momento en que Pablos pide de beber y Jurre, el vizcaíno, le impide satisfacer la sed: "y diéronme un vaso con agua; y no le hube bien llegado a la boca, cuando, como si fuera lavatorio de comunión, me le quitó el mozo espiritado que dije" (pp. 38-39). El fragmento menciona explícitamente la ceremonia del lavatorio que consiste en la ablución de los dedos que practica el sacerdote después de haber preparado el cáliz, durante el ofertorio de la misa. Aquí la persona que interfiere es un "mozo espiritado", es decir, "posseído del espíritu maligno", expresión equivalente a "estar endiablado u endemoniado" según el Diccionario de Autoridades ${ }^{36}$.

ne y su sangre, para que quien le come viva eternamente. Por esto cualquiera que le usa a menudo y con devoción fortalece de manera la salud y la vida de su alma, que es casi imposible sea emponzoñado de ninguna suerte de mala afición o depravado intento" (pp. 1794-1795).

35 Alberto Magno, Opera Omnia, al cuidado de Auguste Borgnet, L. Vives, Paris, 1890, t. 38, p. 488.

${ }^{36}$ Ed. cit., t. 2, pp. 607-608. Quevedo utiliza el término espiritado con el significado de "endemoniado" también en el Canto segundo del "Poema heroico de las necedades y locuras de Orlando": "Y diciendo, y haciendo, y 
El pasaje de la cena contiene de nuevo la referencia a la comunión desacralizada y esta vez el protagonista es el mismo licenciado cabruno: "Llegó la hora de cenar... cenamos mucho menos, y no carnero, sino un poco del nombre del maestro: cabra asada" (p. 40). Al clérigo, "maestro" de gramática, se le describe como si fuera Cristo, el "Maestro", rodeado de sus discípulos; la cena nos trae inmediatamente a la memoria la Última Cena bíblica y el acto de comer la carne del "maestro", la Eucaristía, en que ocurre la transubstanciación, o sea el cambio del pan y del vino en el cuerpo y sangre de Jesucristo. Pero aquí el banquete místico está completamente invertido: el alimento que se come es la "cabra asada" del demonio, la carne del rumiante cocida con el fuego, que evoca la imagen del infierno. Arnold Rothe, además de notar las alusiones eucarísticas que hemos escudriñado y su forma "abiertamente blasfémica", concluye: "Pero como el licenciado Cabra mismo participa en la cena, él se come en cierta manera a sí mismo..."37. Nótese que el narrador pone el acento en que la comida no es carnero, animal que en el simbolismo cristiano es el emblema del sacrificio de Cristo para la salvación de la humanidad, ya que "le bélier sacrifié à la place du Fils obéissant devienne une figure du divin Crucifié; qu'on symbolise jusqu'au buisson où l'un embarasse ses cornes, pour y voir les branches d'épines dont l'autre daigna se laisser couronner..."38. Hay otra referencia al carnero en un pasaje anterior del Buscón donde Cabra distribuye a cada uno

en volandas, / salta sobre el caballo y arremete / con acciones furiosas y nefandas, / y como espiritado matasiete" (Obra poética, ed. J. M. Blecua, Castalia, Madrid, 1969-1981, t. 3, p. 443, vv. 345-348). El verbo espiritar aparece en La culta latiniparla: "Conque en muy poco tiempo, sin maestro, por sí sola, cualquier mujer se puede espiritar de lenguaje y hacerse enfadosa, como si toda su vida lo hubiera sido, que los propios diablos no la puedan sufrir; y es probado" (Obras completas, t. 1, p. 421); y el sustantivo espíritus se emplea en La fortuna con seso y la hora de todos: "Al ruido salió el marido, y viéndola, creyó que eran espíritus que se le habían revestido, y partió de carrera a llamar quien la conjurase" (Obras completas, t. 1, p. 262, las cursivas son mías).

37 "Comer y beber en la obra de Quevedo", Quevedo in perspective, ed. J. Iffland, Juan de la Cuesta, Newark, DE, 1982, p. 213.

38 M. L'AbBÉ Auber, Histoire et théorie du symbolisme religieux avant et depuis le christianisme, Fechos et Letouzey, Paris, 1884, t. 2, p. 86. Louis BRÉHIER también señala que "à la place de l'agneau on trouve parfois le bélier qui a sa double signification. Un sarcophage romain représente la séparation des boucs et des béliers, mais le bélier est aussi la figure du Christ et c'est le rôle qu'il a déjà dans le sacrifice d'Abraham; ses cornes sont comparées à la cou- 
de los estudiantes: "tan poco carnero, que, entre lo que se les pegó a las uñas y se les quedó entre los dientes, pienso que se consumió todo, dejando descomulgadas las tripas de participantes" (p. 37). Américo Castro explica que "la excomunión de participantes era la que caía sobre quienes trataban con un excomulgado" 39 y B. W. Ife precisa que "the excommunicate may not take part in Holy Communion and so will receive nothing through the mouth, and, as Quevedo says, all the meat went no further than the teeth and fingernails" 40 . La mención de la "descomunión" y la no ingestión del carnero reafirman la naturaleza diabólica del dómine. La continuación de la segunda escena del refectorio es significativa: "Mire v. m. si inventara el diablo tal cosa. — «Es cosa saludable» —decía— «cenar poco, para tener el estómago desocupado»; y citaba una retahíla de médicos infernales" (p. 40). Aquí el texto asocia claramente a Cabra con el demonio, asociación que se repite poco después: "Mas ordenólo el diablo de otra suerte, porque tenía una [melecina] que había heredado de su padre, que fue boticario" (pp. 43-44). San Juan Crisóstomo, uno de los Padres de la Iglesia a quien Quevedo cita con mucha frecuencia ${ }^{41}$, en varios sermones condena el pecado de la avaricia y parangona a los avaros a los "dæmoniaci", como por ejemplo en la homilía 81: "Vultis in medium adducamus dæmoniacos et avaros, et utrosque comparemus?" 42 . San Gregorio Magno dictamina que el "antiquus hostis", alias el diablo, tentó al primer hombre con la "gula, vana gloria et avaritia" 43 y para describir la codicia usa la metáfora del fuego ${ }^{44}$.

ronne d'épines et c'est pour cette raison qu'il orne les monuments les plus divers..." (L'art chrétien: son développement iconographique des origines à nos jours, H. Laurens, Paris, 1918, p. 70).

39 Anotación a El Buscón, Espasa-Calpe, Madrid, 1967, p. 36.

40 Anotación a su edición citada de La vida del Buscón, p. 205.

${ }^{41}$ Véase Sagrario López Poza, "Quevedo y las citas patrísticas”, BBMP, 67 (1991), 75-156

42 Commentarius in Sanctum Matthœum Evangelistam, al cuidado de J. P. Migne, Paris, 1857-1866, t. 58, p. 734.

43 Homiliarum in Evangelia, PL, t. 76, p. 1136.

44 "Venter quippe iniqui avaritia est, quia in ipsa colligitur quidquid perverso desiderio glutitur. Liquet vero quia avaritia desideratis rebus non exstinguitur, sed augetur. Nam more ignis cum ligna quæ consumat acceperit, accrescit; et unde videtur ad momentum flamma comprimi, inde paulo post cernitur dilatari" (Moralium Libri, PL, t. 75, p. 1093). 
El narrador termina el retrato de Cabra con una definición conceptista que da al personaje un valor arquetípico: el licenciado "era archipobre y protomiseria" (p. 34). En cuanto al segundo epíteto, la palabra miseria significa no sólo la pobreza extremada, amplificación semántica del primer término, sino también la codicia, como nos informa Covarrubias: "En nuestro castellano algunas vezes vale estrecheza o avaricia" 45 . En Virtud militante el avaro es definido "disçípulo de Judas" (p. 172), el cual, para Quevedo, continuador de la tradición bíblica y patrística, es el "maestro" de ese vicio, el protoavaro. El Evangelio de San Juan establece la conexión entre el apóstol y el diablo: Cristo revela la traición del Iscariote dándole el pan mojado y, en las palabras del evangelista, "post buccellam, introivit in eum Satanas" $(13,27)$. San Juan Crisóstomo también imputa a Judas el ser el exemplum de la avaricia y así amonesta a los avaros: "Audite omnes avari, qui Judæ morbo laboratis; audite et cavete vobis ab illo morbo" y en la homilía 28 asimila a los endemoniados a Judas: "Quid enim tale faciunt dæmoniaci omnes, quale ausus est Judas, extremam aggressus iniquitatem?" 46 . Entonces, la figura de Judas reúne en sí, de manera particularmente marcada, la avaricia y lo demoníaco y esta doble peculiaridad sugiere la posibilidad de que haya sido el modelo para la creación del licenciado Cabra. Quevedo menciona numerosísimas veces al apóstol traicionero, tanto en sus obras en prosa como en su poesía, prueba de su profundo interés por los aspectos emblemáticos de la personalidad del Iscariote. Algunos pasajes remiten directamente al Evangelio de San Juan, por ejemplo los siguientes:

¿Queréis ber quán sumamente perverso es el avariento? Pues atended a que luego que reziuió de la mano de Christo el regalo en la zena al instante reziuió a Satanás en su alma... Mirad lo que junta en su corazón: disposiçión halageña para el arrepentimiento, i la grazia, i demonio, i infierno. Literalmente entiendo deste lugar que abren la voca a la mano de Dios, i juntamente el corazón a Satanás (Virtud militante, p. 173).

Y con ser Cristo el señor del banquete, y él mismo la comida, y sus apóstoles los convidados -en la mesa más sagrada y de mayores

45 Op. cit., p. 807. El Dicc. Aut. también afirma que miseria "significa assimismo avaricia, mezquindad y demasiada parsimonia”.

46 Commentarius in Sanctum Mattheum Evangelistam, PG, t. 58, p. 727 y t. 57 , p. 356 . 
misterios, y donde se instituyó el Sacramento por excelencia, la Eucaristía, que es don de la gracia, se entró Satanás en el corazón de Judas (Política de Dios y gobierno de Cristo).

El más sagrado convite que vieron la tierra y el cielo fue el de la cena de Cristo; y cuando Dios y Hombre sacramentado se entraba por las bocas de sus discípulos, se entró Satanás en el corazón de Judas (La constancia y paciencia del Santo Job $)^{47}$.

Judas aparece también en el Buscón, a propósito de los robos de Pablos: "Yo era el despensero Judas, que desde entonces hereda no sé qué amor a la sisa este oficio" (p. 76). Además, uno de los rasgos fisiognómicos del licenciado Cabra es el "pelo bermejo" (p. 32), color que en la sociedad española de los siglos XVI y XVII daba a una persona una "caracterización moral... globalmente perversa" como escribe Fernando González Ollé48, y que la tradición popular atribuía a Judas: "Rubicundo era Judas el traidor: ni mujer ni hombre, ni perro ni gato de aquella color"49. El mismo Quevedo, en un soneto titulado "A Judas Iscariotes, ladrón no de poquito", observa con sarcástica complacencia: "Bien está lo bermejo a lo ahorcado"50. Si la avaricia y el amor al dinero por parte del apóstol fueron los móviles de la traición y la consiguiente muerte de Cristo, el dómine Cabra es el más fiel "discípulo" de Judas ya que su ciega codicia determina el fallecimiento de un "pobre mozo". El "platicante", llamado para asistir al moribundo, confirma que "la hambre le había ganado por la mano en matar aquel hombre" (p. 46). Esa hambre que, según el narrador, Cabra "parecía que tenía por pecado el matarla” (p. 50), mata a una víctima inocente de la avaricia. Por consiguiente se podría afirmar que el clérigo es el verdadero "despensero Judas" del Buscón, y no Pablos, que roba para sobrevivir. Cuando el estudiante ve la hostia sacramenta-

47 Obras completas, t. 1, pp. 619 y 1488.

48 "Fisiognómica del color rojizo en la literatura española del Siglo de Oro", RLit, 43 (1981), p. 153.

49 Refranero general ideológico español, p. 646.

50 Obra poética, t. 2, p. 22, v. 5. QuEvEDo se refiere al color "bermejo" y su asociación con Judas también en El sueño del infierno o Las zahúrdas de Plutón. Cuando uno de los alguaciles protesta contra el castigo que le infligen los diablos por haber vendido "al justo", el narrador dice entre sí: “-¿Al justo vendistes? Éste es Judas. Y lleguéme con codicia de ver si era barbinegro o bermejo, cuando le conozco, y era un mercader, que poco antes había muerto" (Obras completas, t. 1, p. 164). 
da - "el Sacramento"- que alguien le administra, pronuncia unas palabras reveladoras: "Señor mío Jesucristo, necesario ha sido el veros entrar en esta casa para persuadirme que no es el infierno" (p. 46). Estas palabras insisten en la antítesis entre los aspectos infernales del pupilaje y del pupilero que lo dirige y la Eucaristía, de modo que la parte conclusiva del capítulo 3 del libro primero del Buscón representa lo sagrado versus lo satánico, lo cual es el leitmotiv de todo el episodio del licenciado Cabra.

$\mathrm{Al}$ concluir nuestro análisis, resulta evidente que la elección del nombre Cabra tiene mucho más que ese "algo de adrede indicativo" señalado por Spitzer. La lectura de las isotopías denotativas y connotativas del texto nos ha permitido descubrir la presencia de claves simbólicas subyacentes, cuyo desciframiento es esencial para comprender a fondo el personaje quevediano y la compleja estrategia narrativa del escritor. El intento artístico de Quevedo no ha sido simplemente caricaturizar la figura del avaro, sino más bien mostrarnos la naturaleza diabólica de la "peste" de la avaricia, por medio de un proceso de inversiones de símbolos y valores, sobre todo de los de la tradición cristiana. A la manera de los emblematistas ${ }^{51}$ don Francisco ha pintado el retrato del arquetipo del avaro endemoniado, que ha hecho de la enseñanza de Judas su única religión y modelo de vida.

FRANCESCO TARELLI

The University of Nebraska at Lincoln

51 Véase el artículo de Héctor E. Ciocchini, "Quevedo y la construcción de imágenes emblemáticas”, RFE, 48 (1965), 393-405. 